\title{
Study on microstructure and thermal conductivity of semi-solid die casting aluminum alloy
}

\author{
Zengrong $\mathrm{Hu}^{1,3}$, Xiaonan $\mathrm{Wang}^{2,3}$, Xiaming Chen ${ }^{2,3}$, Pengcheng Huan ${ }^{3,4}$, Weihua $\mathrm{Li}^{1}$, and \\ Nagaumi Hiromi ${ }^{2,3, *}$ \\ ${ }^{1}$ School of Rail Transportation, Soochow University, Suzhou, Jiangsu, 215131, China \\ ${ }^{2}$ School of Iron and Steel, Soochow University, Suzhou, Jiangsu, 215131, China \\ ${ }^{3}$ High-performance Metal Structural Materials Research Institute, Soochow University, Suzhou, \\ Jiangsu, 215131, China \\ ${ }^{4}$ State Key Laboratory of Rolling and Automation, Northeastern University, Shenyang, Liaoning, \\ 110819, China
}

\begin{abstract}
Keywords: semi-solid die casting $\mathrm{AlSi}_{8}$, microstructure, thermal property.
\end{abstract}

\begin{abstract}
In order to improve the comprehensive properties of casting aluminum, and to fulfill the requirements of forming thin wall fins for communication products, mechanical stirring was employed to prepare the semi-solid aluminum alloy AlSi8. communication products were produced by the semi-solid die casting process. The microstructure and mechanical and thermal properties were studied. The test results show that the microstructure of semi-solid die-casting samples changes from dendrite to globular microstructure, and the average tensile strength, elongation and thermal conductivity are $220 \mathrm{MPa}, 7 \%$ and $170 \mathrm{~W} /(\mathrm{m} * \mathrm{~K})$, respectively, which is significantly higher than that of the common die-casting samples. It was proved that the semi-solid die casting technology can be used in actual production and improve the products quality.
\end{abstract}

\section{Introduction}

The communication technology is updated and the data transmission speed is growing rapidly. Now 5G network will be commercial application soon. In 5G(five generations) network practical application, mobile phone with phased array antenna will transmit signals to base station and microcellular base station, and the base station and microcellular base station will communicated with phased array antenna to realize signal connection. Compared with the previous four generations of communication technology, 5G network will further improve the communication transmission speed, more emphasis on continuous wide area coverage, high capacity of hot spots, which will inevitably require communication elements

\footnotetext{
*Corresponding author: zhanghai888jp@suda.edu.cn
} 
to be able to withstand higher voltage, higher power density and higher operating temperature. Therefore, base station elements, such as filter housings, are required to have better heat dissipation performance. In response to the requirements of high thermal performance, communication enterprises have improved their design, using raw materials with higher thermal conductivity, optimized structural design of filter housing, etc., using thinner fins to increase the cooling area, and requiring suppliers to adopt improved technology to further improve the cooling performance.

Therefore, the die-casting manufacturers actively adopt semi-solid die-casting technology for the new requirements of $5 \mathrm{G}$ communication products. The so-called semi-solid die casting refers to the process of solidification of liquid metal, in which mechanical or electromagnetic methods are used for strong stirring, so that the dendrite network framework easy to form in common casting is broken to form a dispersed granular structure, so as to make semi-solid liquid metal, and then die-casting it into billets or castings. Compared with the traditional casting, it has the advantages of smooth filling, greatly reducing porosity, casting shrinkage and thermal deformation; long die life, and small tendency of mold adhesion. Due to the strong filling capacity of semi-solid slurry, it is particularly conducive to the forming of thin-walled parts, and the mechanical properties of the thick and thin parts of the products are similar, and isotropic. It is especially suitable for the high performance requirements of aluminum alloy die casting in communication and other industries. In this paper, the microstructure and thermal conductivity of AlSi8 aluminum alloy semi-solid die casting parts are studied.

\section{Experiments}

The original experimental material is alsi8 ingot, and its nominal chemical composition is shown in Table 1.After melting the raw material (Electromagnetic induction furnace), take a proper amount of molten metal from the holding furnace, mix it with a mechanical mixing head, and then die-casting to obtain the corresponding parts.

Table 1. The chemical compositions of AlSi8 aluminum alloy.

\begin{tabular}{lcccccccc}
\hline $\mathrm{Fe}$ & $\mathrm{Si}$ & $\mathrm{Cu}$ & $\mathrm{Mg}$ & $\mathrm{Mn}$ & $\mathrm{Zn}$ & $\mathrm{Ti}$ & $\mathrm{Pb}$ & $\mathrm{Sn}$ \\
\hline $0.5 \sim 1.2$ & $6.0 \sim 9.0$ & 0.1 & 0.35 & 0.3 & 0.1 & 0.2 & 0.08 & 0.05
\end{tabular}

Phase analysis was carried out by X-ray diffractometer (XRD, Bruker D8 focus X-ray diffractometer). The microstructure of AlSi8 die casting material was observed and characterized by Hitachi s-4800 field emission scanning electron microscope. LECO $\mathrm{M}-400-\mathrm{H}$ microhardness tester was used for microhardness testing, the load was $100 \mathrm{~g}$ and the load holding time was $10 \mathrm{~s}$. Netzsch DSC 200f3240-20-1008-1 was selected to test the thermal diffusivity and then calculated the thermal conductivity.

\section{Results and discussion}

Figures 1a and $\mathrm{b}$ are optical microscope images of the polished and etched metallographic specimens. It can be seen from the figure that the overall grain has been transformed into a more obvious ball shape, and the change of grain size is small. This shows that the mechanical mixing process before die casting does play a role of semi-solid pulping, but the short-term and insufficient and uneven mixing makes the dendrite broken evenly, and in the process of solid-liquid mixture entering the mold for die casting and cooling, the solid-phase grains that were originally broken by stirring no longer change significantly, while the 
liquid-phase part is in the process of cooling crystallization It is possible to produce larger and more irregular grains.

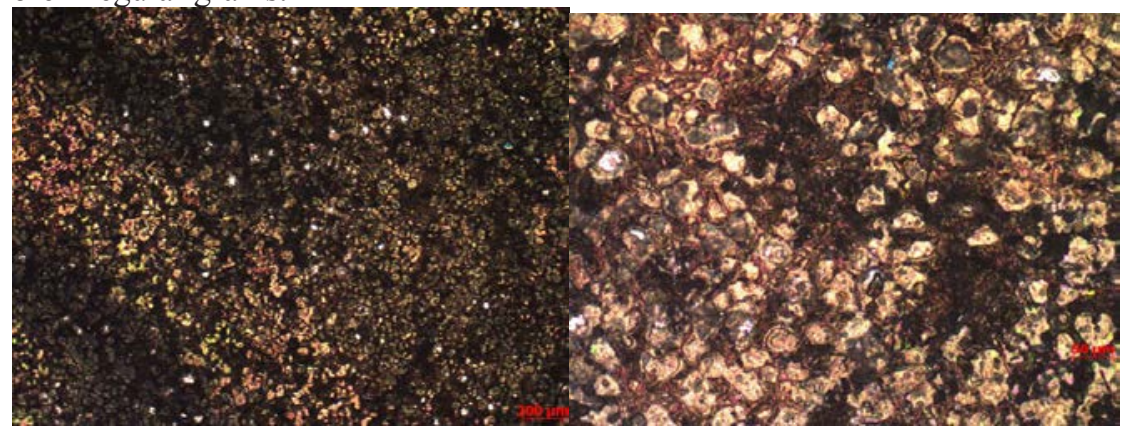

Fig. 1. Optical microscope images of AlSi8 semi-solid die casting part of, (a) and (b) different magnification.

Fig. 2a is another optical microscope image of the semi-solid die casting part. It can be seen from the image that there are relatively obvious dendrites left in the middle area. Compared with Fig. 2b, it can be found that the normal die-casting is dendrites, while the picture of semi-solid die-casting sample obviously has spherical grains. Compared with the metallographic pictures of semi-solid die casting in the relevant literature, the semi-solid die casting effect was not so good, and this process needs to be improved greatly.

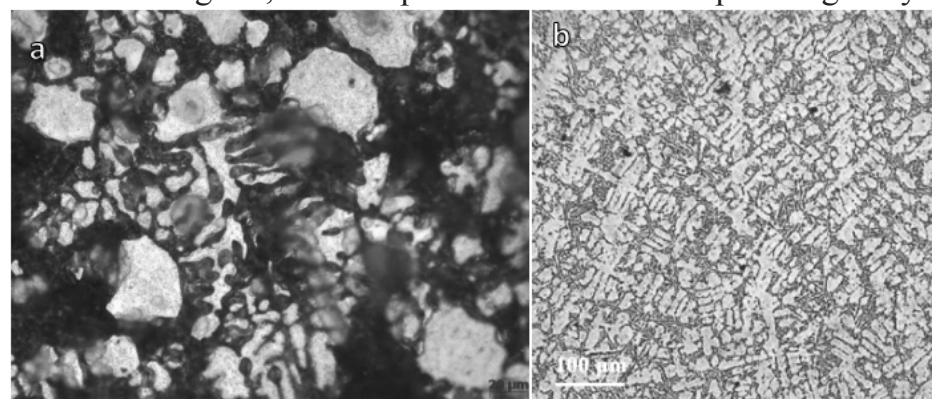

Fig. 2. Metallography, (a) AlSi8 semi-solid die casting sample, (b) AlSi8 normal die casting sample.

Fig. 3 is the XRD patterns of alsi8 semi-solid die casting sample. The peaks of aluminum, aluminum silicide and manganese silicide can be seen from the figure. It indicates that these components are contained in the sample. However, other elements in the nominal composition of the alloy are not reflected on the XRD diagram, which may be due to the lower content of these elements

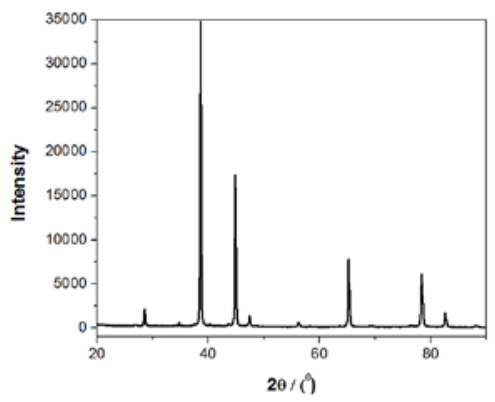

Fig. 3. XRD patterns of AlSi8 semi-solid die casting sample. 

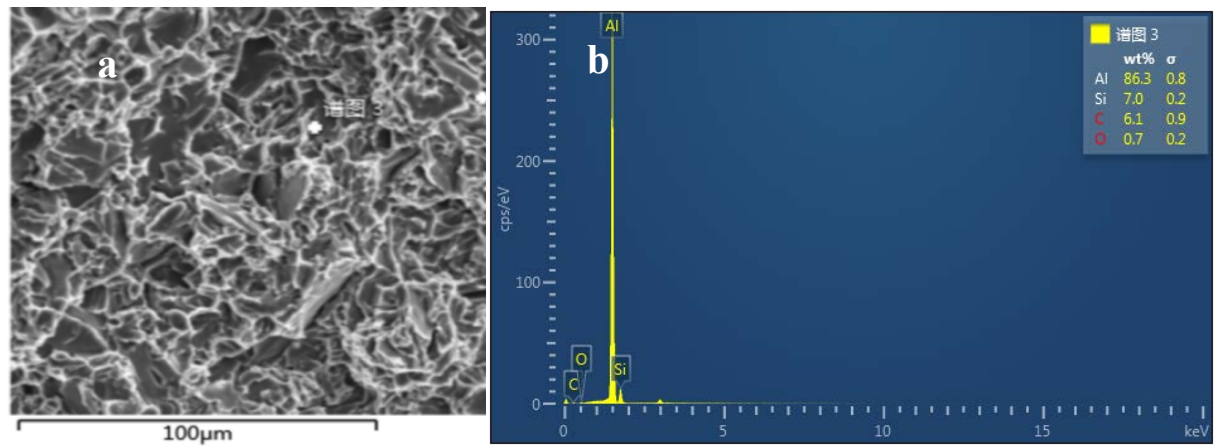

Fig. 4. EDS test result of AlSi8 semi-solid die casting sample.

Fig.4a is the SEM image of the cross section of AlSi8 semi-solid die casting sample. It can be found that the microstructure is relatively uniform. This means the semi-solid process was effectively reduced the grain size.

And Fig.4b was the point EDS analysis of Fig.4a. The result shows that the main elements content in the sample were Aluminum and Silicon. It was consistent with XRD test result.

Fig. 5 is the Vickers hardness result of the corresponding sample. Before the test, grind the sample with 1000 grit sandpaper to obtain a flat and smooth measuring area. The average Vickers hardness was $89.5 \mathrm{HV}$. The hardness of normal die casting AlSi8 alloy is generally $60 \mathrm{HV}$. That is the hardness of semi-solid die-casting material is obviously improved. As we all know, hardness is a reflection of the comprehensive properties of metal materials. Hardness has a certain relationship with its strength. Generally speaking, the material with high hardness has high strength. This shows that the semi-solid die casting process can improve the mechanical properties of die-casting materials. This can also be verified by tensile test results.

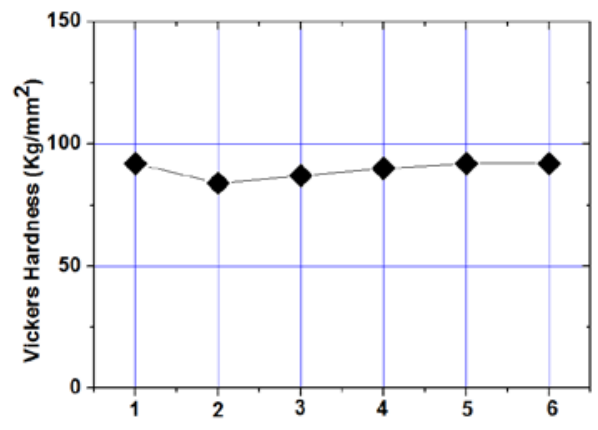

Fig. 5. The vickers hardness of AlSi8 semi-solid die casting sample.

Fig. 6 is the tensile test result of the corresponding sample. The size of the tensile specimen is shown in the inset picture, and the thickness is $2 \mathrm{~mm}$. The average tensile strength of the sample is $220 \mathrm{MPa}$. The average tensile strength of normal die casting AlSi8 alloy is $190 \mathrm{MPa}$. The tensile strength of different samples has a little difference, but the elongation is obviously different. The minimum elongation is $4.54 \%$, and the maximum is $11.2 \%$, which may be caused by the internal defects of the material or the irregular shape of the grain size. This shows that the semi-solid die casting process used in this experiment needs further improvement. 


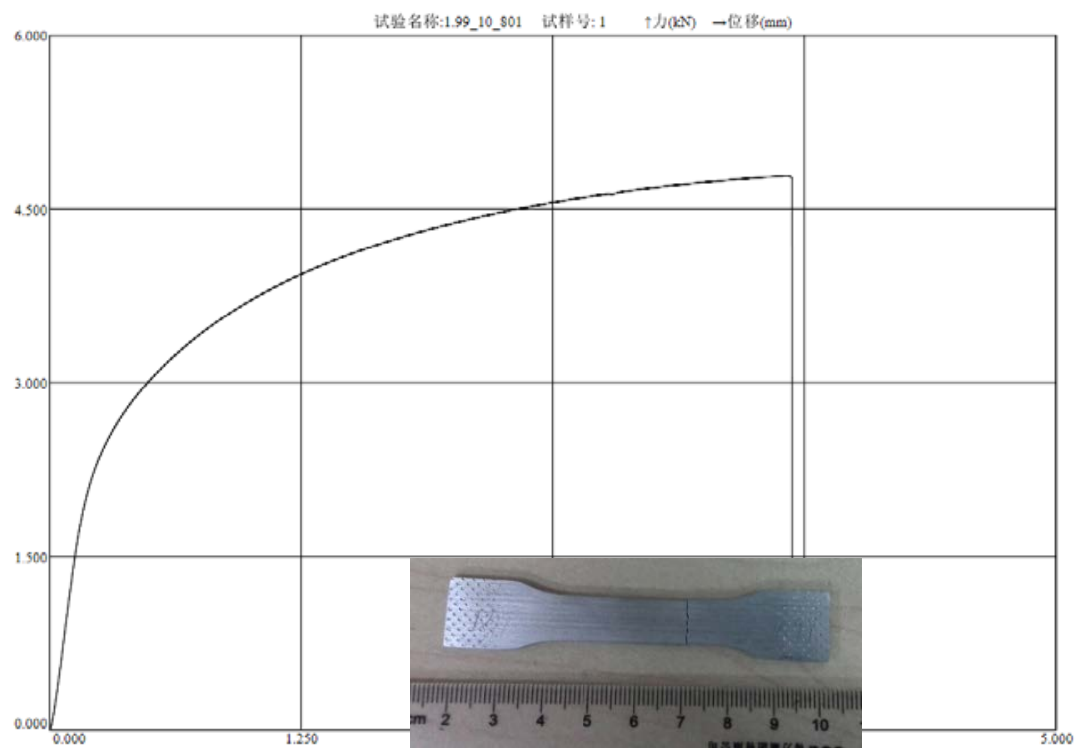

Fig. 6. Tensile test curve of AlSi8 semi-solid die casting sample.

The thermal and electrical properties of semi-solid die casting AlSi8 alloy were tested. The specific heat of materials was measured by Netzsch DSC $200 \mathrm{f} 3$ differential calorimeter, and the specific heat was $0.882 \mathrm{j} /(\mathrm{g} * \mathrm{~K})$. Using the specific heat results and the thermal diffusivity measured by the laser flash method, the average thermal conductivity of the sample was calculated. It was $167.063 \mathrm{~W} /(\mathrm{m} * \mathrm{~K})$. The specific values of each sample are shown in Table 2 . The conductivity of the sample was measured by FET-D60K digital metal conductivity meter, and the conductivity was $19.7 \mathrm{MS} / \mathrm{m}$.

Table 2. Thermal conductivity test results of semi solid die casting of AlSi8 alloy.

\begin{tabular}{llll}
\hline Sample No. & $\begin{array}{l}\text { Thermal diffusivity } \\
\mathrm{mm}^{\wedge} 2 / \mathrm{S}\end{array}$ & $\mathrm{Cp}$ & Thermal conductivity \\
& 69.998 & 0.882 & $\mathrm{~W} /(\mathrm{m} * \mathrm{~K})$ \\
1 & 70.288 & 0.882 & 166.699 \\
2 & 70.166 & 0.882 & 167.389 \\
3 & 70.151 & 0.882 & 167.101 \\
4 & & 167.063 \\
\hline
\end{tabular}

\section{Conclusion}

Communication products were prepared by mechanical stirring semi-solid die casting technology. The microstructure and mechanical properties of the parts were studied. The metallographic picture shows that the microstructure of the material has been mainly spherical structure. However, due to the short mixing time, uneven and insufficient mixing in the actual production operation, there are still obvious dendrites left in certain areas of the material. Compared with the common die casting process, the microhardness and tensile strength of the semi-solid samples are obviously improved. This shows that the semi-solid process can improve the material properties, but the process in this paper needs to be optimized and improved. 


\section{Reference}

1. [1Jung $\mathrm{H} \mathrm{K}$, Kang $\mathrm{C}$ G. Induction heating process of an $\mathrm{Al}-\mathrm{Si}$ aluminum alloy for semi-solid die casting and its resulting microstructure[J]. 2002, 120(1-3):355-364.

2. Jung B J , Sato T, Tezuka H, et al. Microstructure and mechanical properties of an Al-7\% $\mathrm{Si}-0.5 \% \mathrm{Mg}$ alloy produced by semi-solid process[J]. Journal of Japan Institute of Light Metals, 1998.

3. Gencalp S, Saklakoglu N . Effects of Low-Frequency Mechanical Vibration and Casting Temperatures on Microstructure of Semisolid AlSi_8Cu_3Fe Alloy[J]. Arabian Journal for Science and Engineering, 2012, 37(8):p.2255-2267.

4. Mao W, Bai Y, Tang G . Preparation for Semi-Solid Aluminum Alloy Slurry under Weak Electromagnetic Stirring Conditions[J]. JMST, 2006, 022(004):447-451. 